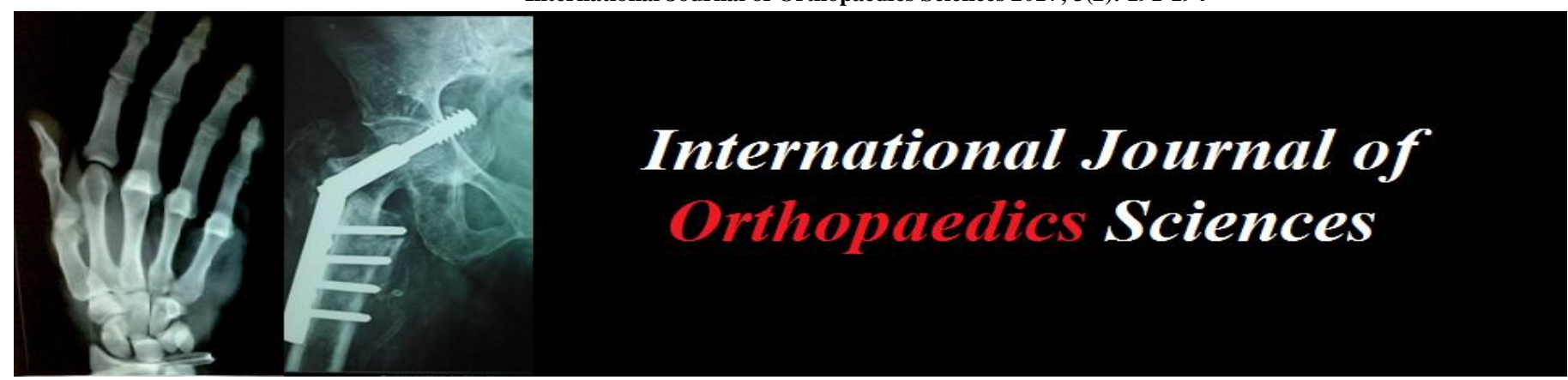

ISSN: $2395-1958$

IJOS 2017; 3(2): 191-194

(C) 2017 IJOS

www.orthopaper.com

Received: 30-02-2017

Accepted: 31-03-2017

Raju Karuppal

Additional professor, Dept. of Orthopaedic, Govt. Medical

College, Kozhikode, Kerala, India.

Sandhya Somasundaran

Assistant Professor, Dept. of Ophthalmology, Govt. Medical College, Kozhikode, Kerala, India.
Correspondence

Raju Karuppal

Additional professor, Dept. of

Orthopaedic, Govt. Medical

College, Kozhikode, Kerala,

India.

\section{Functional outcome of Ilizarov ring fixation in infected non-union tibia: A prospective study}

\section{Raju Karuppal and Sandhya Somasundaran}

DOI: http://dx.doi.org/10.22271/ortho.2017.v3.i2c.30

\section{Abstract}

Bone loss and sequestration are the two difficult situations in infected nonunion of Tibia, which poses many challenges in its treatment. Evaluation of functional recovery and bone healing in infected nonunion of tibial diaphysis treated by Ilizarov method.

20 patients with infected nonunion of tibial shaft fractures. All patients had undergone previous surgeries and they were treated by sequestrectomy, soft tissue debridement and stabilization by Ilizarov. Those had bone defect were treated by corticotomy and bone lengthening as well. Functional evaluation was performed by the timed performance tests of walking speed, sit-to-stand, stair climbing and Toronto Extremity Salvage Score (TESS). Union achieved in all cases. Functional recovery could be achieved over short time after the Ilizarov ring removal. The improvements were faster and statistically very much significant ( $\mathrm{p}$ value 0.0001). Infected non-unions of tibia can be effectively treated by Ilizarov ring fixation. The observation of delayed recovery is valued for advising similar patients about the expected period of functional recovery and to continue the stretching and strengthening exercises during this period.

Keywords: Infected nonunion, Ilizarov, Functional assessment, Toronto Extremity Salvage Score

\section{Introduction}

Fractures of tibia are very common in patients with trauma; many of them are open and complex type because of its subcutaneous position. The nonunion is often associated with infections, shortening, deformity, and poor condition of the skin. The deformities are also often complex and may include translation, angulation, and rotation of the components ${ }^{[1]}$. Ilizarov fixator is a recommended surgical procedure to correct the angular deformities, shortening and to achieve union at the infected non-union site ${ }^{[2]}$. The advantage of early weight bearing follows Ilizarov fixator, consider as a best surgical indicator in such cases ${ }^{[3]}$. The own disadvantages like the unusual cosmetic look, cumbersome and the prolonged periods in the frame are very well outweighed by its advantages ${ }^{[4]}$.

The most important factor in the successful treatment is not only the eradication of infection or the bony union, but the restoration of the function as well. Of the existing many methods that measures physical function from the patient's perspective follows the limb salvage surgeries, Toronto Extremity Salvage Score is the most useful one ${ }^{[5]}$. TESS is a diseasespecific questionnaire basically designed to assess physical disability in limb-salvage surgery patients.

There are only few studies are available on functional assessment after limb salvage surgeries by the Ilizarov method. This prospective, longitudinal study documents the functional abilities of 20 patients with infected nonunion of tibia treated by Ilizarov technique.

2. Materials and Methods: We conducted a prospective study of patients who presented to our unit with infected nonunion of unilateral tibia. Between July 2009 and April 2015, 20 patients underwent thorough soft tissue and bony debridement followed by stabilization with Ilizarov frame.

2.2. Inclusion Criteria: Adult patients (aged 20-60), capable of providing consent and complying with the outcome instruments who had infected non union of unilateral tibia at the diaphysis. 


\subsection{Exclusion Criteria:}

Patients with bilateral involvement, neurological or vascular deficit, uncontrolled diabetes mellitus, spinal deformities, cardiac failure and any other diseases of the legs. Patients were not excluded on the basis of previous surgeries or duration of the present problem.

All cases were already treated previously before referral, with various treatment modalities like plaster of paris (POP) cast, functional brace, external fixators, internal fixation with plates, $\mathrm{K}$ nail, interlocking nail etc. We assessed them in detail preoperatively for knee and ankle instabilities and range of motion. They were also evaluated radiologically according to the standard work up for Ilizarov technique. Before proceeding to the procedure, they were counseled, worked up and pre-operative functional assessments were also completed by the performance tests. Figure 1 provides an outline of the study design.

All patients were operated by a single surgeon as per the standard protocols. All were subject to standard preoperative optimization, postoperative care and physiotherapy. Cases were followed up to a period of at least 24 months.

Patients were allowed to sit and stand on the day one itself. Walking (full weight bearing) with or without the aid of axillary crutches is allowed. Pin site cleaning is taught to every patient and he/she was also allowed to take bath. Distraction was started on 7-10 th post-operative day. Close follow up was given with radiographs to assess the regenerate at corticotomy site and the status of union. Functional capability of the subjects was evaluated by the TESS at 6 weeks 3, 6, and 12 months post operatively (Figure 1).

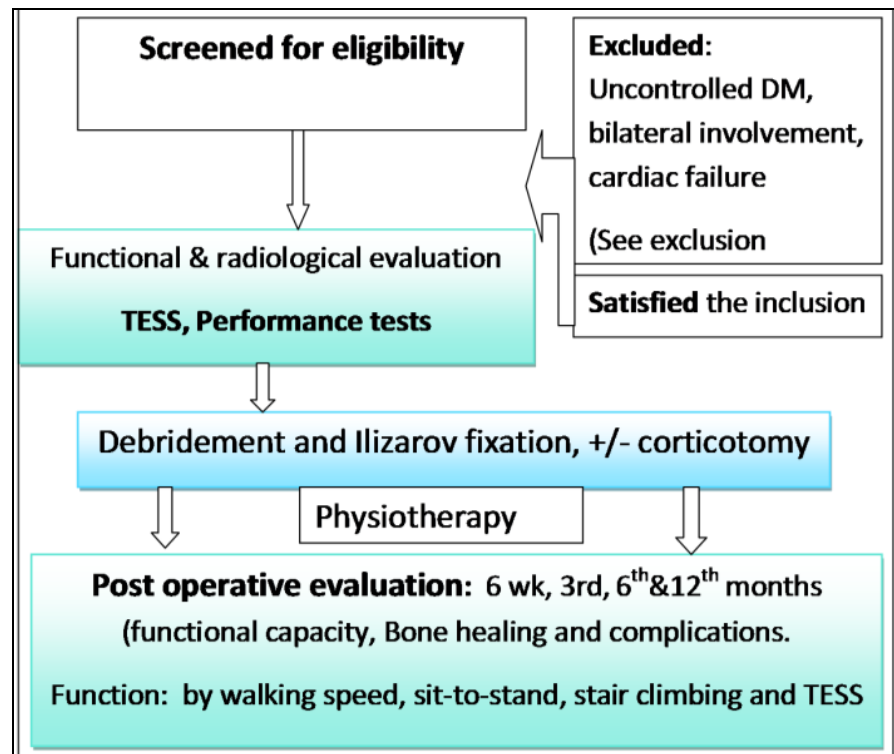

Fig 1: The detailed descriptive outline of the study design, which shows the schematic pathway through which the patient being selected, evaluated, intervened and functionally evaluated finally.

2.4. Statistical Analysis: The outcome data was analyzed by a Bio statistician using the SPSS Statistics version II.

\section{Results}

The demographic details, including the age and the previous treatments are shown in Table 1. Of the 20 patients, $90 \%$ are male (18/20), and all of them were victims of road traffic accidents. Majority were managed by wound debridement and external fixator stabilization, followed by POP casting (45\%) before referral to us. Fifty percentages of them had an infected wound over the fracture area (10/20), all were healed without any special reconstructive procedures. The commonest deformity found in them was ankle equinus; in about 18 patients $(90 \%)$ which was also completely corrected by an additional foot assembly.

Table 1: The demographic details of the study group

\begin{tabular}{|c|c|c|c|}
\hline & Total & male & female \\
\hline No of patients & 20 & 18 & 2 \\
\hline $20-30$ years & $20 \%$ & 4 & 0 \\
\hline $30-40$ years & $25 \%$ & 3 & 2 \\
\hline $40-50$ years & $35 \%$ & 7 & 0 \\
\hline $50-60$ years & $20 \%$ & 4 & 0 \\
\hline Previous treatments taken & & & \\
\hline WD \& POP cast alone & $10 \%$ & 02 & 0 \\
\hline WD \& POP & $5 \%$ & 01 & 0 \\
\hline WD \& Exfix $\rightarrow$ POP cast & $45 \%$ & 07 & 2 \\
\hline WD \& Exfix $\rightarrow$ Plating & $5 \%$ & 01 & 0 \\
\hline WD \& Exfix $\rightarrow$ Nailing & $25 \%$ & 05 & 0 \\
\hline WD \& Nailing & $5 \%$ & 01 & 0 \\
\hline WD \& $\rightarrow$ Plating $\rightarrow$ Nailing & $5 \%$ & 01 & 0 \\
\hline
\end{tabular}

WD- Wound debridement, POP - Plaster of paris, Exfix - External Fixator

The individual details in relation to the corticotomy distraction is summarized and shown in Table 2. Average duration of Ilizarov fixator application was 108 days (range 60-182 days). The bone gap was ranged from $0-8.2 \mathrm{cms}$ (mean $3.9 \mathrm{cms}$ ) and amount lengthening as percentage of limb segment was an average of $9.3 \mathrm{cms}$ (range 4.3-2.2 cms). The mean lengthening index and fixation Index were 22.2 and 68 respectively (ranges 5.9-82 and 23.6-280). Bony union achieved in all patients at variable time segment depending on the bone defect (mean 86 days).

Table 2: Summary of details in relation to the corticotomy distraction.

\begin{tabular}{|c|c|c|}
\hline & Mean & Range \\
\hline Age (Years) & 38.5 & $25-52$ \\
\hline Amount Lengthened/gap (cm) & 3.9 & $0-8.2$ \\
\hline Amount Lengthened as \% of limb segment & 9.3 & $4.3-2.2$ \\
\hline $\begin{array}{c}\text { Lengthening index (Days of } \\
\text { lengthening/Amount lengthened) }\end{array}$ & 22.2 & $5.9-82$ \\
\hline $\begin{array}{c}\text { Fixation Index (Days in fixator/ Amount } \\
\text { lengthened) }\end{array}$ & 68 & $\begin{array}{c}23.6- \\
280\end{array}$ \\
\hline $\begin{array}{c}\text { Total length of time in External fixator } \\
\text { (Days) }\end{array}$ & 108 & $60-180$ \\
\hline
\end{tabular}

Table 3: Summery of the functions at various intervals.

\begin{tabular}{|c|c|c|c|c|}
\hline & $\begin{array}{c}\text { Mean recovery ratios } \\
\text { M }\end{array}$ & $\begin{array}{c}\text { 3- } \mathbf{6} \\
\text { months }\end{array}$ & $\begin{array}{c}\text { 6 months } \\
-\mathbf{1} \text { Yr }\end{array}$ & 1-2 Yrs \\
\hline $\begin{array}{c}\text { TESS score } \\
(\%)\end{array}$ & $\begin{array}{c}1.06(1.07- \\
1.23)^{\mathbf{x}}\end{array}$ & $\begin{array}{c}1.15(1.07- \\
1.30)^{\mathbf{x}}\end{array}$ & $\begin{array}{c}1.70(1.12- \\
1.84)^{\mathbf{y}}\end{array}$ & $\begin{array}{c}1.98(1.06- \\
2.20)^{\mathbf{y}}\end{array}$ \\
\hline $\begin{array}{c}\text { Walking } \\
\text { speed(m/s) }\end{array}$ & $\begin{array}{c}0.5 .(0.3-1) \\
\mathbf{x}\end{array}$ & $\begin{array}{c}1(8.10- \\
1.21)^{\mathbf{x}}\end{array}$ & $\begin{array}{c}1.2(1.06- \\
1.50)^{\mathbf{y}}\end{array}$ & $\begin{array}{c}1.9(1.09- \\
1.99)^{\mathbf{y}}\end{array}$ \\
\hline $\begin{array}{c}\text { Sit to stand } \\
(\text { NO. in 60 }\end{array}$ & $\begin{array}{c}1.08(0- \\
\text { S) }\end{array}$ & $\begin{array}{c}1.7(1.00- \\
2)\end{array}$ & $2(1 .-3)^{\mathbf{y}}$ & $4(3-6)^{\mathbf{x}}$ \\
\hline $\begin{array}{c}\text { Stair } \\
\text { climbing } \\
(\text { No. in 60 S) }\end{array}$ & $1(0-2)$ & $2(1-3)$ & $4(3-5)^{\mathbf{y}}$ & $10(6-13)^{\mathbf{y}}$ \\
\hline
\end{tabular}

${ }^{\mathrm{x}} \mathrm{p}<0.05{ }^{\mathrm{y}_{\mathrm{p}}}<0.0001$

The functional recovery after leg-lengthening surgery at various treatment intervals are shown in Table 3. The performance tests of walking speed, sit-to-stand and stair 
climbing were used, since it represents the basic activities of our daily life and it can easily accomplished in the hospital settings as well. The TESS questionnaires had been provided when the patients were came to the hospital for their follow up checkup. Twenty patients were completed the timed tests at a standardized interval from the date on which the Ilizarov fixator was removed. Paired t-test was used on the absolute score within each interval of recovery in order to compare the significance between scores at the different intervals.

There was improvement in the performance tests between the pre-operative evaluation periods to three months after the Ilizarov frame removal. Thereafter, the functional improvements were faster and statistically significant ( $\mathrm{p}$ value 0.0001 ). The walking speed at one year was increased by 0.7 $\mathrm{m} / \mathrm{s}$ and patients could complete 4 more sit-to-stand repetitions, climb 10 more stairs and had improved their TESS score by $1.98 \%$ points, compared with their initial measurements. Such differences have been reported to be clinically significant. During the mean follow-up of 24 months, none our patients were re-operated or died.

\section{Discussion}

Infected non-union is a challenging issue to both the patient and surgeon. Most often the patient has undergone one or more number of surgical procedures (mean of 1.8 operations at the time of admission in our patients), has lost considerable time and money for that. Moreover the mental and physical trauma to the patient on repeated and prolonged treatment is often underestimated. The bony union must be attained with correction of axial and rotational mal-alignment for the normal kinematics of the limb ${ }^{[6]}$. All of our cases where referred from the secondary level orthopedic centers after one or two procedures. It has been suggested by many authors that early referral to the tertiary centers should be made, if the results are not going in the good way ${ }^{[7]}$.

We found, all our patients had definite radiological features of chronic osteomyelitis at the time of their referral itself. Magadum MP et al recommended about the management of large tibial defects by acute docking followed by bone transport ${ }^{[8]}$, we also have the same opinion after this study. Our data supports the use of Ilizarov technique as a good limb salvage procedure for infected nonunion tibia with bone loss / shortening.

In the past, the functional assessments were evaluated by various ways such as the Short Form-36 (SF- 36) ${ }^{[9]}$ or the Reintegration into Normal Living Index ${ }^{[10]}$. Now, the TESS is considered as the gold standard functional assessment tool follows a limb salvage procedure ${ }^{[11]}$. The main advantage of TESS is considered as, the surgeon-reported outcomes can be subjected to bias while the patient-reported outcomes usually never be so ${ }^{[11]}$. This study assessed the function using TESS, where all of our patients showed almost similar pattern of functional improvement. At three months after removal of the frame, the functional scores showed no significant improvement from the pre-operative score. The objective measurements in the further follow up showed, a statistically significant improvement usually seen after one year ( $p$ value 0.0001). The TESS score has improved by $7.5 \%$ points between one and 24 months, this change is both clinically and statistically significant.

The work of Barker KL et al. ${ }^{[12]}$ also showed the sluggish recovery during the early period after frame removal and greatest between 6 months and 12 months. He pointed out that, significant improvement will continue only up to, but not beyond two years. We believe, the reason for much earlier functional recovery in our patients might be due to their early involvements in some type of physical work after they were discharged from the hospital, because all of them belonged to low socioeconomic group. This encourages us to motivate our patients to do some kind of work affordable to their physical conditions.

Additionally our finding of significantly longer time taken for recovery to occur is important (one year after the ring removal). This significant improvement achieved after one year has a very important implications in the treatment of similar patients. Because this information helps to advise similar patients in future about the expected period of functional recovery, and to continue the stretching and strengthening exercises during this period. We found some of our patients had varying degrees of knee and ankle joint stiffness. Though knee stiffness was usually reduced with physiotherapy, foot and ankle stiffness persisted in few to a certain degree, which could be reason for the moderate functional results in some cases.

Few of our patients had minor complications in relation to the Ilizarov assembly; the commonest was pin site infection. The limitations of our study was the small sample size, hence we recommend formulation of larger studies, so that our results can be confirmed at a larger scale.

5. Conclusion: Infected non-unions of tibia can be effectively treated by Ilizarov ring fixation, which can offer optimal functional results. Early weight bearing is the key factor that separates it from other methods of fixation; hence, it promotes an early functional recovery. The functional scores show appreciable improvement only after 3 months of Ilizarov ring removal. This observation of delayed recovery is valued for advising similar patients about the expected period of functional recovery and to continue the stretching and strengthening exercises during this period.

6. Acknowledgements: We thank all our patients who cooperated with carry out this project.

\section{Abbreviations used}

TESS -Toronto Extremity Salvage Score

POP - Plaster of paris

\section{References}

1. Bhandari M, Guyatt GH, Swiontkowski MF, Schemitsch EH. Treatment of open fractures of the shaft of the tibia. J Bone Jt Surg Br. 2001; 83(1): 62-68.

2. Lee DK, Anh Duong ET, Chang DG. The Ilizarov method of external fixation: current intraoperative concepts. AORN J. 2010; 91(3): 326-340.

3. Pavolini B, Maritato M, turelli L, Arienzo M. The Ilizarov fixator in trauma. J Orthop Sci. 2000; 5:108-113.

4. Ayed A, Al Shahrani, SBOS, Jaya Shanker Tedla, Ph.D., Irshad Ahmad, Ph.D. Effectiveness of ilizarov frame fixation on functional outcome in aseptic tibial non-union cases at Abha, Kingdom of Saudi Arabia: An experimental study. Journal of Taibah University Medical Sciences. 2015; 10:216-221.

5. Davis AM, Wright JG, Williams JI et al. Development of a measure of physical function for patients with bone and soft tissue sarcoma. Qual Life Res. 1996; 5:508-16.

6. Kempf I, Grosse A, Rigaut P: The treatment of no infected pseud arthrosis of the femur and tibia with locked intramedullary nailing. Clin Orthop. 1986; 212: 
$142-545$.

7. Patil S, Montgomery R. Management of complex tibial and femoral nonunion using the Ilizarov technique, and its cost implications. J Bone Joint Surg Br. 2006; 88(7):928-32. 10.1302/0301-620X.88B7.17639.

8. Magadum MP, Basavaraj Yadav CM, Phaneesha MS, Ramesh LJ. Acute compression and lengthening by the Ilizarov technique for infected nonunion of the tibia with large bone defects. J Orthop Surg (Hong Kong). 2006; 14(3):273-9.

9. KMJ Thijssens, JEHM Hoekstra-Weebers, RJ Van Ginkel, HJ Hoekstra. Quality of life after hyperthermia isolated limb perfusion for locally advanced extremity soft tissue sarcoma, Annals of Surgical Oncology, 2006; 13(6): 864-871.

10. R. Nagarajan, R Mogil, JP Neglia, LL Robison, KK Ness. Self-reported global function among adult survivors of childhood lower-extremity bone tumors: a report from the Childhood Cancer Survivor Study (CCSS), Journal of Cancer Survivorship. 2009; 3(1):59-65.

11. Mark Clayer, Simon Doyle, Nicole Sangha, Robert Grimer. The Toronto Extremity Salvage Score in Unoperated Controls: An Age, Gender, and Country Comparison. Sarcoma. Volume. 2012; 5:2012.

12. Barker KL, Lamb SE, Simpson AH. Functional recovery in patients with nonunion treated with the Ilizarov technique. J Bone Joint Surg Br. Jan. 2004; 86(1):81-5. 